\begin{tabular}{lc|}
\hline KURNAL ANALIS KESEHATAN & Klinikal Sains 7 (2) (2019) \\
KLIVERSITAS & KLINIKAL SAINSALSAINS \\
ABDURRAB & http://jurnal.univrab.ac.id/index.php/klinikal \\
\hline
\end{tabular}

\title{
HUBUNGAN MASA KERJA DENGAN KADAR KOLINESTERASE DALAM DARAH PETANI DI DESA PASIRHALANG, CISARUA, KABUPATEN BANDUNG BARAT
}

Gita Nur Fajriani, Suci Rizki Nurul Aeni, dan Viky Cahyo Handoko

Program Studi DIII Analis Kesehatan Sekolah Tinggi Ilmu Rajawali Bandung Jl. Rajawali Barat No. 38 Bandung 40184

Telp. 022-6079141

gitanurfajriani@gmail.com

\section{Info Artikel}

Sejarah Artikel:

Diterima September 2019

Disetujui November 2019

Dipublikasikan

Desember 2019

Keyword :Masa kerja:

Kolinesterase; Pestisida;

\begin{abstract}
Abstrak
Perkembangan di bidang pertanian tidak terlepas dari peran pestisida yang digunakan untuk memberantas hama. Namun penggunaan berkelanjutan menimbulkan keracunan khususnya bagi petani. Keracunan pestisida dapat diamati dari berkurangnya kadar kolinestarase dalam darah. Penelitian ini bertujuan untuk mengetahui hubungan antara masa kerja bertani dengan kadar kolinesterase dalam darah petani. Penelitian dilakukan dengan metode cross sectional dengan 43 sampel petani di Desa Pasirhalang Kecamatan Cisarua, Kabupaten Bandung Barat. Masa kerja petani yaitu $51,2 \%$ sudah bekerja lebih dari lima belas tahun dan $48,8 \%$ bekerja kurang dari lima belas tahun. Kategori kadar keracunan pestisida petani yaitu 14\% mengalami keracunan ringan (kadar kolinesterasi 50 - <75\%) dan 86\% normal (kadar kolinesterasi 75 - 100\%). Hasil uji statistik menggunakan uji korelasi Spearman menunjukkan tidak terdapat hubungan yang signifikan $(\operatorname{sig}=0,567)$ antara masa kerja dengan kadar kolinesterase dalam darah petani di Desa Pasirhalang Kecamatan Cisarua, Kabupaten Bandung Barat.
\end{abstract}

Kata Kunci: masa kerja, kolinesterase, pestisida.

\section{Abstract}

Development in agricultural field can not be separated from pesticides, used to eradicate pests. Continuely use by farmer caused poisoning, that can be measured by cholinesterase levels in blood. This research tried to identify correlation between work period and cholinesterase level in farmer's blood. Research was carried using cross sectional method with 43 farmers from Desa Pasirhalang Kecamatan Cisarua, Kabupaten Bandung Barat. Farmer's work periods were $51,2 \%$ that have work more than 15 years and $48,8 \%$ that have work less then 15 years. Poisoning levels were $14 \%$ severe poisoning $(50-<75 \%$ cholinesterase level) and $86 \%$ normal (75 - 100\% cholinesterase levels). Correlational statistic using Spearman test showed that there was no significant correlation between work period and cholinesterase levels in farmer's blood. 


\section{PENDAHULUAN}

Kesehatan merupakan hal yang sangat penting agar manusia dapat bertahan hidup dan melakukan aktivitas. WHO (1947) mendefinisikan kesehatan sebagai keadaan mental, fisik dan kesejahteraan sosial yang berfungsi secara normal tidak terjangkit suatu penyakit. Di Indonesia Sektor pertanian menjadi salah satu bidang terpenting bagi masyarakat dikarenakan Indonesia merupakan negara agraris, yang mayoritas penduduknya bercocok tanam (Ipnawati et al., 2016). Menurut UU RI No.19 Tahun 2013 tentang perlindungan dan pemberdayaan pertani, petani adalah warga negara Indonesia perorangan atau beserta keluarga yang melakukan usaha tani dibidang tanaman pangan, holtikultura, perkebunan dan peternakan.

Hasil pertanian sebagian besar digunakan untuk bahan pangan masyarakat Indonesia. Hasil komoditi pertanian yang meningkat tidak terlepas dari peran pestisida yang digunakan untuk mengendalikan hama seperti serangga, jamur dan lain-lain agar kualitas produksi petanian melimpah, bermutu dan mengurangi kerugian. Demi meningkatkan hasil pertanian petani menggunakan pestisida dengan komposisi, takaran dan frekuensi penyemprotan dilakukan tanpa perhitungan yang benar (Ipnawati 2016) sehingga menimbulkan berbagai masalah baru terutama masalah kesehatan.

Organisasi Kesehatan Dunia (WHO) memperkirakan kasus keracunan pada pekerja pertanian karna pestisida sebanyak tiga juta per tahun dengan tingkat kematian 220.000 jiwa. Penyemprotan merupakan metode aplikasi pestisida yang paling banyak digunakan. Diperkirakan 75\% pestisida diaplikasikan dengan cara disemprotkan (Djojosumarto, 2008). Penggunaan pestisida secara berlebihan dan tidak terkendali seringkali memberikan resiko keracunan pestisida bagi petani. Resiko keracunan pestisida tergantung peran dosis pestisida, lamanya waktu paparan pestisida, dan pengunaan APD (Istianah, 2017). Resiko keracunan pestisida disebabkan oleh penggunaan dan pengelolaan pestisida yang tidak benar, tingkat pengetahuan rendah tentang bahaya pestisida, minimnya penggunaan APD serta tidak memperhatikan cara yang baik dan aman dalam penggunaannya. Resiko keracunan dapat diminimalisir dengan cara membatasi waktu kerja petani dengan pestisida.

Semakin lama waktu kerja dan semakin sering melakukan penyemprotan, maka akan semakin besar kemungkinan untuk mengalami keracunan pestisida. Petani yang bekerja dalam jangka waktu yang lama dengan pestisida akan mengalami keracunan menahun, artinya semakin lama bekerja maka akan semakin bertambah jumlah pestisida yang terabsorbsi dalam tubuh (Rustia et al., 2010). 
Gita Nur Fajriani, Suci Rizki Nurul Aeni, dan Viky Cahyo Handoko / Jurnal Analis Kesehatan Klinikal Sains 7 (2) (2019)

Gejala-gejala keracunan pestisida seperti timbulnya gerakan-gerakan otot tertentu, pupil atau cela iris mata menyempit menyebabkan pengelihatan kabur, mata berair, mulut berbusa dan berair liur banyak, sakit kepala, pusing, detak jantung cepat, mual, muntah-muntah. Deteksi dini mengenai keracunan pestisida dapat dilakukan dengan pemeriksaan kolinesterase untuk mencegah gangguan kesehatan yang kronis dan mematikan (Prasetya et al., 2010).

Kolinesterase adalah suatu enzim yang terdapat pada cairan seluler, yang fungsinya menghentikan aksi asetilkolinesterase dengan jalan terhidrolisis menjadi kolin dan asam asetat. Asetilkolin adalah suatu neuro hormon yang terdapat antara ujung-ujung syaraf dan otot, sebagai media kimia yang fungsinya meneruskan rangsangan syaraf atau impuls ke reseptor selsel otot dan kelenjar atau kolinesterase berfungsi sebagai pengatur kerja saraf dalam menyeimbangkan sistem saraf dalam tubuh.

Desa Pasirhalang merupakan daerah dengan mayoritas warganya berprofesi sebagai petani. Menurut Balai Pertanian Perkebunan dan Kehutanan tahun 2015, Desa Pasirhalang merupakan salah satu daerah penghasil sayuran di Bandung. Hal tersebut dikarenakan letak Desa Pasirhalang yang berada di kaki Gunung Burangrang yang sangat subur dan cocok untuk ditanami berbagai macam tanaman sayuran. Berdasarkan survey awal, petani di Desa Pasirhalang sebagian besar menggunakan pestisida untuk meningkatkan hasil tani.

Mengingat bahaya pestisida jika digunakan menahun, maka perlu dilakukan penelitian mengenai tingkat keracunan pestisida pada petani yang sudah lama bekerja menggunakan pestisida. Penelitian ini bertujuan untuk menganalisis hubungan antara masa kerja dengan kadar kolinesterase dalam darah petani di Desa Pasirhalng Kecamatan Cisarua, Kabupaten Bandung Barat.

\section{METODE}

Metode penelitian yang digunakan dalam penelitian ini metode survei analitik dengan pendekatan survei analitik cross sectional (Notoatmodjo, 2010). Penelitian ini dilakukan untuk mengindentifikasi hubungan masa kerja dengan kandungan kadar enzim kolinesterase dalam darah petani di Desa Pairhalang, Kecamatan Cisarua. Variabel bebas dalam penelitian ini adalah lamanya masa kerja petani. Variabel terikat dalam penelitian ini adalah kadar enzim kolinesterase dalam darah petani. Populasi dalam penelitian ini adalah petani yang menggunakan pestisida. Sampel dalam penelitian ini adalah 43 responden petani yang menggunakan pestisida di Desa Pasirhalang. Teknik Pengambilan sampel dalam penelitian ini menggunakan teknik acak sederhana (simple random sampling).

Teknik pengumpulan data dan jenis data yang digunakan dalam penelitian ini yaitu data primer dan sekunder. Data primer adalah data yang diperoleh dari hasil pemeriksaan 
Gita Nur Fajriani, Suci Rizki Nurul Aeni, dan Viky Cahyo Handoko / Jurnal Analis Kesehatan Klinikal Sains 7 (2) (2019)

kolinesterase dan wawancara semi berstruktur dengan responden, sedangkan data sekunder didapat dari data jumlah petani yang diperoleh dari Balai Penyuluhan Pertanian, Perikanan, dan Kehutanan (BP3K) di Desa Pasirhalang, Kabupaten Bandung Barat. Data yang dikumpulkan dalam penelitian ini berupa data hasil wawancara dan pemeriksaan labolatorium untuk menentukan kadar kolinesterase dalam darah pada petani di Desa Pasir Halang. Wawancara dilakukan dengan menanyakan sudah berapa lama bekerja sebagai petani.

Alat yang digunakan pada penelitian ini yaitu autoklik, blood lancet, cline pipet, kapas alkohol 70\%, Tintometer Kit Lovibond 2000, dan tabung reaksi. Bahan yang digunakan yaitu acetylcholine perchlorat (ACP) $0,25 \mathrm{gr}$, aquadestilata (bebas CO) $250 \mathrm{~mL}$, dan brom timol blue (BTB) 0,112 gr (sebagai larutan indikator).

\section{Prosedur Kerja}

1. Uji Reagen

Indikator dan larutan substrat diuji dengan darah subyek kontrol normal (seorang yang sehat, yang diketahui tidak terpapar dengan pestisida).

2. Pengambilang Darah

Tabung reaksi berisi larutan indikator disiapkan untuk kontrol dan untuk setiap obyek penelitian yang akan diuji, sampel darah $(0,01 \mathrm{~mL})$ diambil dengan tusukan diujung jari kemudian diambil dengan cline pipet dan dimasukkan dalam tabung reaksi, dicampur hingga homogen.

3. Penambahan Larutan Substrat

Setiap tabung ditambahkan larutan substrat 0,5 cc yang dimulai dengan tabung kontrol. Pada saat penambahan substrat ke dalam tabung kontrol waktunya dihitung 0 (nol), kemudian dicatat. Substrat sebanyak 0,5 cc kemudian ditambahkan ke tiap tabung dengan urutan setiap satu menit interval dari set waktu 0 (nol).

4. Perbandingan Warna dan Pembacaan Hasil

Setelah penambahan substrat, larutan dalam tabung kontrol dan sampel akan membentuk warna-warna mulai dari hijau sampai kuning. Warna yang terbentuk dibandingkan dengan satu set kaca berwarna baku standar yang dipasang dalam disk pada alat komparator dalam Tintometer kit. Setiap warna baku menyatakan \% aktivitas enzim kholinesterase. Normal (>75\% - 100\%), keracunan ringan pestisida (>50\% - 75\%), keracunan sedang pestisida (>25\% - 50\%) dan keracunan berat pestisida $(0 \%-25 \%)$. Pengukuran aktivitas enzim kolinesterase dilakukan pada kontrol normal dan sampel darah petani yang telah kontak pestisida. 
Gita Nur Fajriani, Suci Rizki Nurul Aeni, dan Viky Cahyo Handoko / Jurnal Analis Kesehatan Klinikal Sains 7 (2) (2019)

\section{HASIL DAN PEMBAHASAN}

Data mengenai masa kerja petani didapat dari hasil wawancara langsung terhadap petani, dengan menanyakan sudah berapa lama petani tersebut bekerja menjadi petani. Distribusi frekuensi masa kerja petani hasil wawancara dapat dilihat pada Tabel 1.

Tabel 1 Distribusi Frekuensi Lama Masa Kerja Menggunakan Pestisida

\begin{tabular}{ccc}
\hline & \multicolumn{2}{c}{ Distribusi Frekuensi } \\
\hline Lama Kerja Jadi Petani & Jumlah & $\%$ \\
\hline Baru (<15 tahun) & 21 & 48,8 \\
Lama ( $\geq 15$ tahun) & 22 & 51,2 \\
\hline Total & 43 & 100 \\
\hline
\end{tabular}

Tabel 1 menunjukan hasil wawancara yang dilakukan di Desa Pasirhalang dapat diketahui $51,2 \%$ petani yang sudah bekerja lebih dari lima belas tahun dan $48,8 \%$ petani yang bekerja kurang dari lima belas tahun, artinya mayoritas penduduk sudah lama bekerja menjadi petani.

Lama masa kerja yaitu lama seorang petani setiap harinya dalam setiap jam dan beberapa hari dalam seminggu dalam satuan hari. Berdasarkan hasil wawancara dan observasi langsung di Desa Pasirhalang pada praktiknya petani di lapangan sudah bekerja cukup lama menjadi petani dan selama melakukan kegiatan pertanian semua petani menggunakan pestisida. Beberapa petani juga mengaku sudah secara turun temurun menjalankan profesi sebagai petani. Salah satu faktor yang mendorong mereka tetap mejalankan profesinya sebagai petani karena tingkat pengetahuan dan pendidikan dalam keluarga yang kurang memadai.

Adapun data mengenai kadar kolinesterase dalam darah petani didapatkan dari pengukuran menggunakan alat Tintometer Kit Lovibond 2000. Distribusi frekuensi hasil pengukuran dapat dilihat pada Tabel 2.

Tabel 2 Distribusi Frekuensi Kadar Kolinesterase dalam Darah Petani di Desa Pasirhalang Kabupaten Bandung Barat

\section{Distribusi Frekuensi}


Gita Nur Fajriani, Suci Rizki Nurul Aeni, dan Viky Cahyo Handoko / Jurnal Analis Kesehatan Klinikal Sains 7 (2) (2019)

\begin{tabular}{|c|c|c|}
\hline Kadar Kolinesterase & Jumlah & Persentase $(\%)$ \\
\hline Keracunan berat $\quad(0-<25 \%)$ & 0 & 0 \\
\hline Keracunan sedang $(25-<50 \%)$ & 0 & 0 \\
\hline Keracunan ringan $(50-<75 \%)$ & 6 & 14 \\
\hline$(75-100 \%)$ & 37 & 86 \\
\hline Total & 43 & 100 \\
\hline
\end{tabular}

Berdasarkan Tabel 2 di atas dapat diketahui mayoritas petani di Desa Pasirhalang memiliki kadar kolinesterase normal (86\%). Sebagian kecil yaitu $14 \%$ mengalami keracunan ringan dengan kadar kolinesterasi antara 50 - <75\%.

\section{Tabel 3 Hubungan Masa Kerja dengan Kadar Kolinesterase dalam Darah Petani di Desa Pasirhalang Kabupaten Bandung Barat \\ Chi-Square Tests}

\begin{tabular}{|c|c|c|c|c|c|}
\hline & Value & df & $\begin{array}{c}\text { Asymptotic } \\
\text { Significance (2- } \\
\text { sided) }\end{array}$ & $\begin{array}{c}\text { Exact Sig. (2- } \\
\text { sided) }\end{array}$ & $\begin{array}{l}\text { Exact Sig. (1- } \\
\text { sided) }\end{array}$ \\
\hline Pearson Chi-Square & $6.343^{a}$ & 1 & .012 & \multirow{6}{*}{.022} & \multirow{6}{*}{.014} \\
\hline Continuity Correction $^{\mathrm{D}}$ & 4.322 & 1 & .038 & & \\
\hline Likelihood Ratio & 8.649 & 1 & .003 & & \\
\hline Fisher's Exact Test & & & \multirow{3}{*}{.013} & & \\
\hline Linear-by-Linear Association & 6.199 & 1 & & & \\
\hline $\mathrm{N}$ of Valid Cases & 44 & & & & \\
\hline
\end{tabular}

Berdasarkan Tabel 3 uji Chi square diperoleh asym sig (2-sided) 0,012 lebih kecil dari nilai alpha $(0,05)$. Hal tersebut menunjukan bahwa terdapat hubungan yang signifikan antara masa kerja dengan kadar kolinesterase dalam darah petani di Desar Pasirhalang Kabupaten Bandung Barat.

Sebagian besar petani di Desa Pasirhalang beranggapan karena sudah lama bekerja menggunakan pestisida sebagian besar sudah merasa terbiasa dan merasa sudah kebal dengan pestisida. Hal ini menyebabkan sebagian petani sudah tidak memperdulikan efek sampir dari pestisida tersebut, seperti melakukan penyemprotan tiga kali dalam seminggu. Semakin sering seorang petani melakukan penyemprotan, maka semakin tinggi pula resiko keracunannya (Afriyanto, 2008). 
Hasil penelitian ini sejalan dengan penelitian sebelumnya yang dilakukan Ipmawati et al. (2016) di Desa Jati Kecamatan Sawangan Kabupaten Magelang menunjukan hasil bahwa 72,5\% petani yang sudah lebih dari satu tahun mempunyai resiko 5 kali lebih besar keracunan pestisida. Sejalan pula dengan penelitian Samosir et al (2017) yang menyebutkan bahwa 95\% petani yang masa kerjanya lebih dari 15 tahun mempunyai peluang beresiko lebih dari 2,3 kali untuk mengalami gangguan keseimbangan tubuh karena keracunan pestisida dibandingkan dengan petani yang masa kerjanya kurang dari 15 tahun.

Petani yang menunjukan keracunan ringan berdasarkan hasil uji kolinesterase sebaiknya beristirahat atau menghentikan terlebih dahulu aktivitas yang berhubungan dengan pestisida, dan jika timbul gejala keracunan segera melakukan pemeriksaan. Rustia et al (2010) menyebutkan bahwa waktu istirahat didasarkan pada beberapa studi diantaranya studi kasuskontrol mengenai pengaruh istirahat terhadap aktivitas kolinesterase mendapatkan hasil bahwa aktivitas kolinesterase dapat pulih kembali dalam dua minggu tanpa bekerja (menyemprot), dengan perincian $61,1 \%$ pulih dalam satu minggu dan $32,4 \%$ pulih dalam dua minggu. Oleh karna itu perbaikan dapat timbul apabila penyemprot diistirahatkan selama beberapa minggu sehingga tubuh dapat mensintesis kembali enzim kolinesterase.

\section{SIMPULAN}

Berdasarkan penelitian yang telah di lakukan di Desa Pasirhalang, maka dapat disimpulkan petani di Desa Pasirhalang memiliki masa kerja 22 petani sudah bekerja lebih dari 51,2\% tahun dan 48,8\% petani bekerja kurang dari 15 tahun. Petani di Desa Pasirhalang 86\% memiliki kadar kolinesterase normal dan $14 \%$ dengan keracunan ringan. Berdasarkan hasil statistik, terdapat hubungan yang signifikan antara masa kerja dengan kadar kolinesterase dalam darah petani di Desa Pasirhalang, dengan asym sig (2-sided) 0,012.

\section{UCAPAN TERIMA KASIH}

Peneliti mengucapkan terima kasih sebesar-besarnya kepada Kepala Desa Pasir Halang KBB beserta jajarannya dan kepada Balai Penyuluh Pertanian, Perikanan, dan Kehutanan (BP3K) Kecamatan Ngamprah Bandung Barat.

\section{DAFTAR PUSTAKA}


Gita Nur Fajriani, Suci Rizki Nurul Aeni, dan Viky Cahyo Handoko / Jurnal Analis Kesehatan Klinikal Sains 7 (2) (2019)

Afrianto. 2008. Kejadian keracunan pestisida pada petani penyemprot cabai di Desa Candi Kecamatan Bandungan Kabupaten Semarang. Tesis Program Pascasarjana Universitas Diponegoro. Semarang.

Djodjosumarto P. 2018. Pestisida dan Aplikasinya. PT Agromedia Pustaka, Jakarta Selatan.

Ipnawati PA, Setiani O, Darundiati YH. 2016. Analisis faktor-faktor yang mempengaruhi tingkat keracunan pestisida pada petani di Desa Jati, Kecamatan Sawangan, Kabupaten Magelang, Jawa Tengah. Jurnal Kesehatan Masyarakat vol. 4, no.1, hh 427-435.

Istianah, Yuniastuti A. 2017. Hubungan masa kerja, lama menyemprot, jenis pestisida, penggunaan APD dan pengelolaan pestisida dengan kejadian keracunan pada petani di Brebes. Public Health Perspective Journal vol. 2, no.2, hh 117-123.

Notoadmodjo S. 2010. Metodologi penelitian kesehatan. PT Rineka Cipta, Jakarta.

Prasetya, E., Wibawa, A.A., Enggrawati. 2010. Hubungan faktor-faktor paparan pestisida terhadap kadar cholinesterase pada pateni penyemptrot tembakau di Desa Karangjati, Kabupaten Ngawi. Jurnal Fakultas Ilmu Kesehatan .Universitas Setia Budi Surakarta.

Rustia HN, Wispriyono B, Susanna D, Luthfiah FN. 2010. Lama pajanan organofosfat terhadap penurunan aktivitas enzim kolinesterase dalam darah petani sayuran Kabupaten Tanggamus. Makara Kesehatan. Vol. 14, no. 2, hh. 95-101.

Samosir, K., Setiani, O., dan Nurjazuli. 2017. Hubungan Pajanan Pestisida dengan Gangguan Keseimbangan Tubuh Petani Hortikultura di Kecamatan Ngablak Kabupaten Magelang. Jurnal Kesehatan Lingkungan Indonesia. Vol. 16, no.2., hh.63-69. 